\title{
The "who" and "how" of detecting glaucoma
}

\author{
WILLIAM C STEINMANN
}

Chronic open-angle glaucoma is a major cause of blindness in the United Kingdom. It is often undetected until very late in the course of the disease when treatment is of no benefit. Therefore early detection of this condition should be a priority of medical care. The Ministry of Health in the pamphlet The Prevention of Blindness identified family doctors as the "key figures in glaucoma detection." 1 Proponents maintained that general practitioners' medical skills were essential to the screening process and that if glaucoma detection were left to the Supplementary Ophthalmic Services the results would be "disastrous."' Others took the opposing view that general practitioners had neither the time nor the tools (tonometers or visual field testers) to screen for glaucoma and that therefore members of the Supplementary Ophthalmic Services should play the major part in screening for glaucoma. ${ }^{3-5}$

A further concern in detecting glaucoma is the fact that there is still no generally accepted screening test. ${ }^{6}$ An important aspect of these two issues is: which practitioners in the United Kingdom are responsible for detecting glaucoma and what screening tests are they using ? This information would be useful not only in defining realistic, future expectations regarding glaucoma screening, but also in defining where current efforts should be made through policy statements and in teaching clinical skills to maximise detection of glaucoma. To determine by what means the diagnosis of open-angle glaucoma is made and by whom patients are referred hospital records of a sequential series of patients with open-angle glaucoma have been reviewed.

\footnotetext{
Department of Community Medicine and General Practice, Oxford University, Oxford

WILLIAM C STEINMANN, MD, MSC, Milbank scholar (present position: assistant professor, Department of Medicine, Department of Research Medicine, University of Pennsylvania, Philadelphia, Pennsylvania 19104, USA)
}

\begin{abstract}
Methods
The Oxford Eye Hospital is the only major eye referral centre in the county of Oxfordshire. For five consecutive months I retrospectively reviewed all hospital case notes of scheduled outpatients there. Every case with a diagnosis or presumptive diagnosis of primary open-angle glaucoma,* ocular hypertension, $\uparrow$ or incomplete glaucoma $\ddagger$ was reviewed in further detail. Each diagnosis was confirmed by documentation of the recorded results from tonometry, fundoscopy, visual field testing, and gonioscopy. The doctor's clinic visit notes, the consultant's letter to the patient's general practitioner, and all referral forms were reviewed for the following information which was recorded:

(1) The health practitioner who referred the patient to the ophthalmologist-for instance, general practitioner, optician; (2) the diagnosis at the time of referral; (3) the test findings that provided a basis for the presumed diagnosis and referral; and (4) the patient's symptoms at the time of referral.
\end{abstract}

\section{Results}

A total of 505 hospital case notes were analysed: primary open-angle glaucoma was diagnosed in 363, incomplete open-angle glaucoma in 59 , and ocular hypertension was documented in 83 . It was possible to identify the referring practitioner in 458 of the 505 cases (table I). Most referrals were from opticians and ophthalmic practitioners. Of the 80 patients in whom the initial detection of glaucoma was made by an ophthalmologist, almost half were found on a return visit for another eye condition. The remainder of these patients first presented as emergencies to the hospital.

The presumed diagnosis of the referring practitioner was ascertained in 270 of the 363 case notes with a confirmed diagnosis of primary open-angle glaucoma (table II). The opticians and ophthalmic practitioners had more often diagnosed glaucoma in the patients with glaucoma that they referred. This pattern is similar for those with

*Defined as the triad of intraocular pressure greater than $21 \mathrm{~mm} \mathrm{Hg}$, cupping of the optic disc, and glaucomatous visual field defect in any eye with an open anterior chamber angle.

†Only intraocular pressure greater than $21 \mathrm{~mm} \mathrm{Hg}$ was present.

†Any one of, or combination of, the components of the triad was present but excluding those with open-angle glaucoma* or ocular hypertension. $\dagger$ 
TABLE I-Proportion of patients with glaucoma who were referred by the various practitioners

\begin{tabular}{lccc}
\hline \multicolumn{1}{c}{ Practitioner } & $\begin{array}{c}\text { Primary } \\
\text { OAG }\end{array}$ & $\begin{array}{c}\text { Incomplete } \\
\text { OAG }\end{array}$ & $\begin{array}{c}\text { Ocular } \\
\text { hypertension }\end{array}$ \\
\hline General practitioner & $65(18 \%)$ & $12(20.5 \%)$ & $25(30 \%)$ \\
Optician or ophthalmic practitioner & $205(56.5 \%)$ & $37(62.5 \%)$ & $24(29 \%)$ \\
Ophthalmologist & $50(13.5 \%)$ & $7(12 \%)$ & $23(27.5 \%)$ \\
Unknown & $43(12 \%)$ & $3(5 \%)$ & $11(13.5 \%)$ \\
\hline Total & $363(100 \%)$ & $59(100 \%)$ & $83(100 \%)$ \\
\hline
\end{tabular}

TABLE II-Status of the referral diagnosis for patients with open-angle glaucoma

\begin{tabular}{llllll}
\hline & & & \multicolumn{2}{c}{ Practitioner type } \\
\cline { 3 - 7 } Diagnosis & & & & $\begin{array}{c}\text { General } \\
\text { practitioner }\end{array}$ & $\begin{array}{c}\text { Optician or } \\
\text { ophthalmic } \\
\text { practitioner }\end{array}$ \\
\hline & & & & & \\
\hline
\end{tabular}

incomplete glaucoma or ocular hypertension, which are not shown. The most common misdiagnoses were "normal," cataract, and "vascular problem." The eye disorders that practitioners correctly identified at time of referral when concurrent glaucoma was missed included cataract, conjunctivitis, and hypertensive retinopathy.

The screening test observation used to make the correct presumptive diagnosis at referral was determined in 290 case notes. The results for the 196 patients with glaucoma are shown in table III. Cupping of the disc seen on ophthalmoscopy most often led to the diagnosis of open-angle glaucoma. This was so for those with incomplete glaucoma but not for those with ocular hypertension. Again, there were 12 referrals for cupping of the disc, and three for ocular hypertension, in which the findings were not confirmed by the consultant ophthalmologist. Three were referred by general practitioners. None of these is included in the study results.

Finally, whether or not the patient was symptomatic was determined in 270 case notes. These results are shown as proportions for each diagnostic category in table IV. Of the patients referred by general practitioners in whom the symptoms state was determined, all were symptomatic at the time of referral. This compares with $64 \%$ of those

TABLE III-Distribution of screening test observations that led to correct presumptive diagnosis of $O A G$

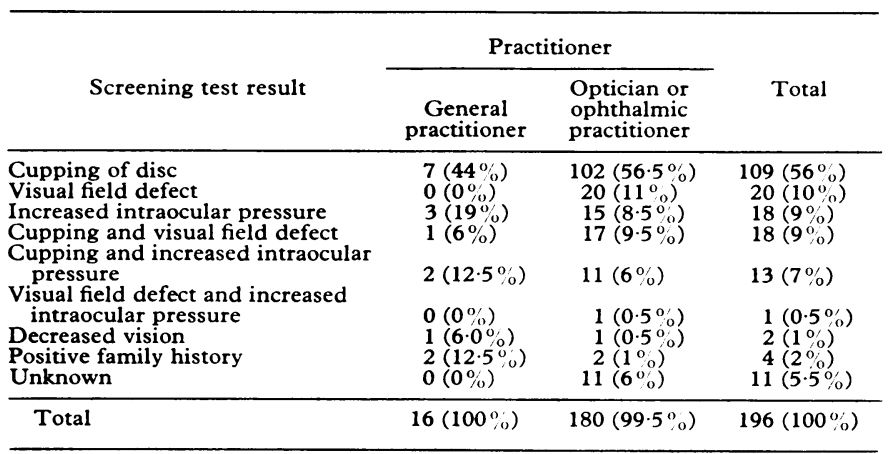

TABLE IV-Proportion of patients who were symptomatic and referred by the various practitioners

\begin{tabular}{lccc}
\hline \multicolumn{1}{c}{ Practitioner } & OAG & $\begin{array}{c}\text { Diagnosis } \\
\text { incomplete } \\
\text { OAG }\end{array}$ & $\begin{array}{c}\text { Ocular } \\
\text { hypertension }\end{array}$ \\
\hline $\begin{array}{l}\text { General practitioner } \\
\text { Optician or ophthalmic practitioner }\end{array}$ & $\begin{array}{c}100 \% \\
64 \%\end{array}$ & $\begin{array}{c}100 \% \\
20 \%\end{array}$ & $\begin{array}{c}100 \% \\
100 \%\end{array}$ \\
\hline
\end{tabular}

referred by practitioners in the Supplementary Ophthalmic Services. The symptoms present at referral were also recorded; "decreased vision" was the most common complaint.

\section{Discussion}

Clearly in Oxfordshire the opticians and ophthalmic practitioners are responsible for detecting most cases of open-angle glaucoma, incomplete glaucoma, and ocular hypertension. Some bias may have occurred in estimating the true role of either practitioner if any initiating action was unrecorded. The accuracy of the case note abstracts was tested in 25 patients with glaucoma who were selected at random and asked during a visit to the clinic how their glaucoma was discovered. Their designation of the responsible practitioner agreed with the case note abstract in every case.

The reasons ophthalmic practitioners and opticians are responsible for most referrals are probably: (1) they conduct their practice with a high level of suspicion for glaucoma and routinely screen for it; (2) they are more effective in their use of available screening tests; or, (3) patients with glaucoma preferentially seek these practitioners for problems that are likely to lead to the diagnosis of open-angle glaucoma-for instance, for eye complaints that may or may not be related to glaucoma.

It is difficult to say which of these are the major contributing factors, but there is evidence that all three play some part. The proportion of asymptomatic patients referred with a diagnosis of glaucoma by the opticians and ophthalmic practitioners suggests a high level of supicion or screening or both. It could be, however, that visual complaints that result in an ophthalmic visit and examination are not volunteered to, or solicited by, the general practitioner. Yet the prevalent symptom of "decreased vision" and others, such as need for a "glasses check," are hardly considered to be those of glaucoma, again suggesting that opticians and ophthalmic practitioners are on the lookout for glaucoma.

These practitioners are also competent in their diagnostic screening for open-angle glaucoma, if judged by the high confirmation rate of their referrals and the low number of falsepositive referrals. The false-negative rate is not known and the false-positives may be underestimated since these patients are likely to be discharged from follow-up and their case notes have not been reviewed in this survey.

The fact that no asymptomatic patient was referred by general practitioners suggests that these practitioners are not routinely screening for glaucoma. The small proportion of cases with the correct referral diagnosis of glaucoma could be explained by a low index of suspicion, faulty screening, or failure to screen at all. Ten patients had been correctly referred for cupping by opticians or ophthalmic practitioners in whom fundoscopic examination had also been performed by the general practitioner. Cupping had been detected by the general practitioner in only one case.

As already suggested, differences in the choice of practitioner by patients may account for the preponderance of the referrals by opticians or ophthalmic practitioners. Nevertheless, the likelihood of a yearly visit to the general practitioner is great. The prolonged early course of glaucoma with ocular hypertension and cupping may precede severe visual field loss by several years. Therefore, routine screening for glaucoma by general practitioners should yield a larger proportion of referrals. General practitioners outnumber opticians and ophthalmic practitioners by roughly 3 to 1 in Oxfordshire.

The importance of the fundoscopic examination in the detection of glaucoma by all practitioners is striking. Few patients with glaucoma were referred because of defects in the visual field or raised intraocular pressure. This suggests that these tests were infrequently used in screening for glaucoma by either group of practitioners. Proportionately, raised intraocular pressure was more often a reason for referrals by general practitioners,

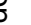

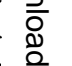

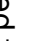

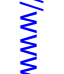
뭉

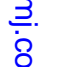
궁 음

\section{.} N

N

(

\section{음}

.

.


although these numbers are quite small. Perhaps of more importance, in only $26 \%$ of the patients with glaucoma referred by general practitioners was a screening test the reason for the referral.

These results show that ophthalmic practitioners and opticians detect most of the glaucoma in patients referred to the Oxford Eye Hospital. The reasons probably include increased suspicion and screening efforts, more effective use of screening tests, and patient choice in seeking care. Regarding the various screening tests, the observation of cupping on fundoscopy was by far the most common means of detecting glaucoma by general practitioners and opticians or ophthalmic practitioners.

Since the eye hospital is the major referral centre for the county of Oxfordshire, these results provide a reasonable basis for broader generalisation of the "who" and "how" of detecting glaucoma in the United Kingdom at present.

Opticians and ophthalmic practitioners should be aware of their role in detecting glaucoma. Perhaps screening for glaucoma should be part of their routine eye examination. General practitioners should realise that the ophthalmoscope may be the only tool needed to enable them to contribute to the detection of glaucoma, provided that they can recognise cupping on fundoscopic examination and foster some degree of suspicion for this disease. The potential role of the fundoscopic examination in screening for glaucoma deserves further evaluation, as does the possible part that general practitioners could play in detecting glaucoma.

J I Mann and M P Vessey at the Department of Community Medicine and General Practice, and Fred Ederer from the National Eye Institute, Bethesda, were extremely helpful in the design of this study. P N Awdry, A J Bron, $\mathrm{H}$ Cheng, and A Freedman, Oxford Eye Hospital, Oxford, kindly granted permission to study their clinic patients. The clerical staff at the Oxford Eye Hospital provided invaluabe help in collecting the data. A K Diehl from the University of Texas, San Antonio, and R S Wigton from the University of Nebraska, Omaha, provided editorial help.

This work was funded by the Milbank Memorial Fund, New York.

\section{References \\ 1 Standing Medical Advisory Committee for the Central Health Services Council and the Ministry of Health. The prevention and alleviation of blindness. London: HMSO, 1962. \\ 2 Briggs AH. Detection of glaucoma. Br Med F 1963;i:256-7. \\ 3 Anonymous. Detection of glaucoma. $\mathrm{Br} \mathrm{Med} \mathcal{F}$ 1963;i:624. \\ 4 Day PP. Detection of glaucoma. Br Med f 1962;ii:1257. \\ 5 Walker WM. Unsuspected chronic glaucoma. Br Med f 1963;ii:1590. \\ ${ }^{6}$ Graham PA. Screening for chronic glaucoma. Proc $R$ Soc Med 1966;59: 1215-20.}

(Accepted 14 April 1982)

\title{
Referral routes to hospital of patients with chronic open-angle glaucoma
}

\author{
J M MACKEAN, A R ELKINGTON
}

\begin{abstract}
An analysis of the referral routes to Southampton Eye Hospital of 191 patients who had been diagnosed as having chronic open-angle glaucoma showed that 121 patients $(63.4 \%)$ were diagnosed as a result of the patient seeking advice for ocular symptoms (118) or because they had a family history of glaucoma (3). Advice had been sought from general practitioners (48), ophthalmic medical practitioners (19), and ophthalmic opticians (46). The remaining eight patients had gone directly to the casualty department. Seventy patients had been identified by chance, the majority by ophthalmic medical practitioners (26) or ophthalmic opticians (32).
\end{abstract}

\section{Introduction}

In 1978 an estimated 10000 people in the United Kingdom were reported blind from the visual field loss due to chronic open-angle glaucoma. ${ }^{1}$ The estimated prevalence figures for the disease in the community vary and depend on the criteria used for diagnosis. ${ }^{2}$ Even the lowest estimate, however, is $0.4 \% .^{34}$

Chronic open-angle glaucoma is essentially a disease of the elderly. These patients often have to cope not only with the

\footnotetext{
University Surgical Unit, University of Southampton, Southampton SO9 5NH

J M MACKEAN, BA, DBo, research fellow

A R ELKINGTON, FRCS, DO, senior lecturer in ophthalmology
}

trials of presbyopia but also with the effects of lens opacities and degenerative changes at the macula. It is thus not surprising that they ascribe any but the most dramatic visual symptoms merely to their age. Against this background of widespread acceptance of failing vision, among this group is superimposed the fact that the earliest visual field loss of glaucoma occurs in the area adjacent to, but not affecting, the visual axis. The resulting islands of visual loss may not be noticed by the patient (especially if the vision of the fellow eye is good) or their effects may be put down simply to advancing years. Even if a defect is noticed the patients have an opportunity to adapt to the defect in their eyesight as the progression of the field loss is usually slow. It is not surprising, therefore, that many patients present late, though some may be fortunate and have the glaucoma suspected by an ophthalmic medical practitioner, a general practitioner, or an ophthalmic optician at a routine eye test.

The purpose of this study was to discover how many, out of a group of patients with chronic open-angle glaucoma, had noticed symptoms and by which route patients with this form of glaucoma were referred to hospital.

\section{Patients and methods}

So far as possible, all patients who lived in the Southampton and South-west Hampshire Health District and who had been diagnosed (between May 1977 and April 1980 inclusive) as having chronic openangle glaucoma were included in the study. The small number of private patients and those living, or had been referred after diagnosis from, outside the health district were excluded. Names were collected from the diagnostic index at Southampton Eye Hospital and from the outpatient clinic at Lymington Hospital.

Details of sex, date of birth, and referral routes were obtained from 